\title{
Degradation of Wetlands on the Qinghai-Tibet Plateau: A Comparison of the Effectiveness of Three Indicators
}

\author{
GAO Jay ${ }^{*}$, LI Xi-lai², CHEUNG Alan', YANG Yuan-wu² \\ 1 School of Environment, University of Auckland, Private Bag 92019, Auckland, New Zealand \\ 2 College of Agriculture and Animal Husbandry, Qinghai University, Xining 810016, China \\ ${ }^{*}$ Correspondence author, e-mail:jg.gao@auckland.ac.nz
}

(C) Science Press and Institute of Mountain Hazards and Environment, CAS and Springer-Verlag Berlin Heidelberg 2013

\begin{abstract}
The Qinghai-Tibet Plateau encompasses a large quantity of wetlands, some of which have been degraded to varying severity levels. In the literature, a number of degradation indicators have been proposed to evaluate ecological health of wetlands, but their effectiveness in the plateau environment remains unknown. In this study, we assessed the effectiveness of three degradation indicators, soil moisture content at $10 \mathrm{~cm}$ deep, vegetative cover, and density of pika burrows. The degradation severity of wetlands in Maduo County on the Qinghai-Tibet Plateau is enumerated at four levels, intact, slight, moderate and severe. Analysis of 106 samples collected in the field demonstrates that the density of pika burrows is the least reliable indicator. By comparison, vegetative cover and underlying soil moisture content are more reliable, even though neither is a perfect indicator as the difference among adjacent levels of severity as revealed by $t$-test is not always statistically significant. The imperfection of vegetative cover as an indicator is due to its variation among different types of wetlands. The limitation of moisture content is attributed to its non-linear relationship with wetland degradation. Above the threshold of about 50\% in moisture content wetlands are unlikely to be degraded. It is recommended that moisture be measured at the point near the surface and vegetative cover be further differentiated by species in order to improve their effectiveness.
\end{abstract}

Keywords: Wetland degradation; Grass cover; Soil moisture; Pika damage; Qinghai-Tibet Plateau

Received: 15 October 2012

Accepted: 27 April 2013

\section{Introduction}

Wetlands are transitional ecosystems between terrestrial and aquatic systems. As invaluable environmental and ecologic resources, they provide many important ecological services, such as lessening the greenhouse effect by taking up and storing carbon (Avis et al. 2011). However, wetlands around the world have suffered degradation and loss, especially in the headwaters region of the Yangtze River. Here wetlands experienced widespread degradation (Zhang et al. 2011), and shrunk by $29 \%$ over the last 40 years with the wetland ecosystems increasingly fragmented at an accelerated pace (Wang et al. 2007). For instance, the Zoige wetland has been seriously degraded (Li et al. 2011). Maqu wetlands in the upper Yellow River reach faced very serious desiccation, shrinkage, and degradation (Qi and $\mathrm{Li}$ 2007). Degraded wetlands in the Qomolangma National Nature Reserve amounted to $71.3 \mathrm{~km}^{2}$, accounting for $1.8 \%$ of the total (Li et al. 2008).

Although wetland degradation is related closely to environment desiccation, such natural changes alone cannot lead to wetland degradation at various severity levels. The interaction of human activities with nature is identified as the leading cause of wetland degradation ( $\mathrm{Li}$ et al. 2010). For instance, wetlands in the source region of the Yellow River are degraded by the joint forces of anthropogenic and natural factors. Long-term 
overgrazing and the destruction by rodents following climate warming accelerated the degradation process (Zhou et al. 2005). Wetland reclamation, water pollution, deficiency of water resources and disastrous climate were blamed for the degradation of coastal wetlands ( $\mathrm{Wu}$ et al. 2009). In particular, wetland reclamation for agriculture is the major reason for the loss of freshwater wetlands (Ma et al. 2009; Teferi et al. 2010).

In order to prevent wetland degradation, it is essential to develop a sound assessment system that can yield early warning of significant wetland stress or degradation. This system should be based on essential and effective indicators of wetland degradation. So far a number of wetland degradation indicators have been used. For instance, Wang et al. (2011) employed hydrogeomorphics (average annual rainfall, soil water content, spatial distance to a water body, geomorphologic type), landscape characteristics (surrounding patch type, landscape type, marsh patch density, leaf area index), and human disturbance (distance to a road, and to farmland) as the indicators in quantitatively assessing wetland health. Van Dam et al. (1998) found that phytoplankton could be potentially the most promising indicator of wetland degradation caused by pollutants. A suite of published ecological indices, such as water quality, wetland macrophyte, and wetland fish, were used for assessing coastal wetlands of the Great Lakes (Cvetkovic and ChowFraser 2011). These indicators, however, are inapplicable to plateau wetlands that have not suffered from pollution.

In grading severity of wetland degradation, $\mathrm{Li}$ et al. (2010) made use of enhanced vegetation index in conjunction with meteorological, socioeconomic, and field data. The validity of vegetation index as an indicator was later confirmed by Gao et al. (2011). They reported a significant difference in vegetation cover, aboveand below-ground biomass between degraded wetlands and intact sites. Normalized difference vegetation index is the most important factor for inducing water loss from the Zoige alpine wetland (Li et al. 2011). Depletion of water reserve from a wetland is a sure sign of its stress that may lead to its eventual degradation. However, this parameter is almost impossible to quantify, and seldom used.
Instead, Zhang et al. (2010) studied the spatial variation of soil moisture in different wetland ecosystems. This review of literature suggests that vegetative cover and soil moisture content are two critical indictors of wetland degradation in the plateau setting. What has been omitted is the role of small mammals in wetland degradation, such as plateau pika (Ochotona curzoniae) endemic to the Qinghai-Tibet Plateau (Arthur et al. 2007). If desiccation causes the sedge mats to dry out, the wetland will be invaded by pikas, even though they are absent in swampy wetlands (Miehe et al. 2011). Moreover, the more degraded the hummocks in the wetland, the larger the pika population. They are a critical agent in aggravating the severity of wetland degradation.

So far no researchers have systematically analyzed the relationship between these indicators and the severity level of wetland degradation. Thus, it remains unknown whether these indicators are effective at revealing degradation severity. This study aims to reveal the effectiveness of the three wetland degradation indicators comparatively. The specific objectives are: (1) to identify critical indicators of wetland degradation on the QinghaiTiber Plateau; (2) to assess the effectiveness of these indicators in revealing the degradation severity of plateau wetlands; and (3) to explore the existence of a critical threshold above which wetland is resilient to degradation in the study site of Maduo County on the Plateau.

\section{Study Area}

Maduo County $\left(33^{\circ} 50^{\prime}-35^{\circ} 40^{\prime} \mathrm{N}\right.$ and $96^{\circ} 50^{\prime}-$ $99^{\circ} 20^{\prime} \mathrm{E}$ ) is located in southern Qinghai Province on the Qinghai-Tibet Plateau, China (Figure 1). Geographically, it measures 228 km (north-east) by $207 \mathrm{~km}$ (north-south), covering an area of 25,253 $\mathrm{km}^{2}$ (Figure 1). Climate on this Plateau is frigid alpine. A large majority of Maduo lies between 4,500 and 5,000 $\mathrm{m}$ a.s.l. At such a high altitude annual temperature averages only $1.2^{\circ} \mathrm{C}$ without distinct seasons. The low temperature regime causes the ground to be frozen most of the year. The growing season is limited to three to four months in the summer season. Natural vegetation in the plateau environment comprises exclusively grasses with limited dwarf shrubs, with grasslands 


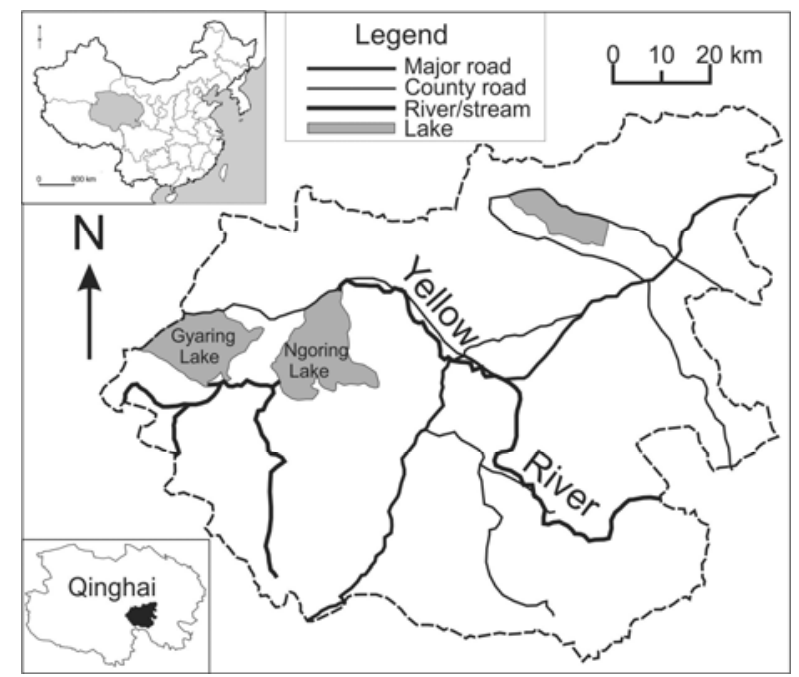

Figure 1 Location of the study site on the Qinghai-Tibet Plateau, China

making up $87.5 \%$ of the entire County. Dominant species of grasses are Kobresia tibetica Maximowicz and Kobresia humilis (C. A. Mey ex Trauvt.) Sergievskaya, with a rooting depth of around $3 \mathrm{~cm}$. Other species of grasses include Poa annua linn and Elymus dahuricus Turcz, and Ligularia virgaurea (Maxim.) Mattf. Their appearance is related to a drier condition.

Due to strong annual evaporation of over 1,260 $\mathrm{mm}$, more than fourfold of the annual rainfall (303.9 mm), Maduo County faces a severe water deficit. Despite this deficit, it is characterized by abundant water resources derived from 13 relatively large rivers within its boundary, the most important being the Yellow River (Figure 1). In addition to these rivers, there are thousands of freshwater lakes with a combined surface area of $1,674 \mathrm{~km}^{2}$. Associated with these rivers and lakes are a huge quantity of wetlands of various types and sizes distributed throughout the County. Some of these wetlands are productive marshy and swampy meadows that are vital grazing resources in winter. Over recent years they have been degraded, even to the severe level (Wang et al. 2007). Main culprits of wetland degradation are identified as long-term unchecked overgrazing, and illegal hunting that broke down the food chain in the 1970s and 1980s when the climate experienced desiccation. The worst degraded wetlands have been turned to denudated land known as "heitutuan" causing the soil erosion problem (Li et al. 2012).

This County has been selected for study because its wetlands have faced the risks of degradation, similar to the azonal K. schoenoides swamps on the Qinghai-Tibet Plateau (Miehe et al. 2011). An understanding of the effectiveness of different degradation indicators is conducive to devising an early warning system of wetland stress and degradation that can be used to prevent further deterioration.

\section{Data Collection and Analysis}

Field work was carried out during 22, 23 and 24 August 2011 with the absence of any antecedent rainfall events. In total, wetlands were inspected at 106 sites widely dispersed throughout the County. Their selection was based on site accessibility and representativeness of wetland types. Although some of them had degraded severely, they were still recognizable from their characteristic wetland features (e.g., residual hummocks, and shallow pan-like depressions). The severity of wetland degradation at each site was assessed by three experts independently of each other without referring to any specific parameters (i.e., just a general impression). It was assigned to one of four pre-determined severity levels of intact, slight, moderate, and severe. Discrepancy between the three severity levels, if applicable, was resolved via mutual consensus.

After the severity level had been assigned, a circle was randomly tossed to the air. The landing position was used for measurement of wetland features within a plot of 3 by $3 \mathrm{~m}^{2}$ in size. The percent grass cover within the plot was estimated visually to an accuracy of $5 \%$. The estimation was undertaken by three experts independently. Their estimates were averaged to yield the final result. Moreover, pictures were taken in the field for indoor confirmation of field estimates. However, the nature of vegetation (e.g., primary or secondary) was not differentiated except a notice of the dominant species of grasses (but not their proportions). Soil moisture content was then measured within the sample plot at $10 \mathrm{~cm}$ below the surface using the Delta-T ML2x ThetaProbe soil moisture sensor to an accuracy of $\pm 1 \%$. A spade was used to remove the top soil and the instrument was inserted into the ground horizontally. The same procedure of measurement was duplicated thrice, each time at a 
unique spot within the sample plot so as to minimize the influence of micro-topographic variations (e.g., inundated ponds and exposed hummocks). All three readings were taken at the same depth within each sample plot, and their mean was used as the final reading. Finally, pika population was counted. Since it was impossible to count pika population accurately (e.g., the inability to count those dwelling inside the burrow), its burrow density was used as a proxy in the field. The collected data were enumerated and statistically analyzed by the severity of wetland degradation in MS Excel ${ }^{\circledR}$. The mean of each severity level was $t$-tested across adjacent severity levels.

\section{Selection of Degradation Indicators}

Although wetland degradation took place on the full continuum from intact to severe inside the study area, it was decided that its severity was enumerated at four specific levels of intact, slight, moderate, and severe for the convenience of discussion. A given level of severity is dictated by the percentage of vegetative cover within the sample plot and its nature, the amount of denudated surface and soil loosened by pika, surface hydrology and moisture content, as well as the number of pika burrows. In the original state, the wetlands are healthy and rich in water reserve without any symptoms of degradation. Their surface is densely covered by original vegetation. Their pristine state shows no signs of human interference or external disturbance except the occasional presence of pika burrows. Slight degradation occurs after the drying up of small pools caused by evaporation and environmental desiccation. It creates a denudated patch rife for the invasion of pikas. Depletion of surface water causes the underlying soil to be relatively dry, as well. Over time the adjacent patches denudated from different burrows will expand and coalesce to a larger patch over the landscape, resulting in a moderate level of degradation. At this level vegetative cover is reduced to about half of the original owing to the continued attacks by pikas. The loosened soil from the pika's digging of burrows piled at the burrow entrance suffocates underneath grass and causes the dying out of native grasses. By this stage the wetland surface is moist only with a low water reserve. As degradation continues, the drier grounds become the welcome spots for the invasion of toxic species of grasses. Such drought-tolerant secondary and unpalatable species can colonize the denudated patches and become established with relative ease as they are not subject to any grazing or disturbance. Loss of fertile soil via water and wind erosion in this fragile environment renders the remaining vegetation more vulnerable to degradation. With the continued removal of the original vegetation, there is no food left eventually. Lack of suitable forage forces pikas to abandon the degraded site and move elsewhere in search of food.

Vegetative cover, soil moisture content, and density of pika burrows are thus identified as indicative of the stage of wetland degradation, and hence its severity. These three factors are deemed comprehensive as they take into consideration biology (grass cover), hydrology (soil moisture content), and soil (pika burrows), all of which are core elements for assessing wetland ecological health (Fennessy et al. 2007). As a matter of fact, hydrology, soil, and biotic community are the most important indicators in rapidly assessing the ecological condition of wetlands (Fennessy et al., 2007). Although soil erosion is not treated as an indicator explicitly, its influence is considered implicitly through grass cover and pika burrow density as the non-grass cover comprises soils loosened by pikas, and the burrowing activity of pikas is associated with soil erosion (Fan et al. 1999). These indicators are useful and practical as they meet the four criteria proposed by Fennessy et al. (2007). Namely, they provide a quantitative measure describing the position of a wetland on the continuum from full ecological integrity (i.e., intact) to highly degraded (poor condition), and are easy and quick to measure on the site, and replicable. The last quality is important in that the results are objective and comparable across different geographic areas and for different types of wetland.

\section{Results}

\subsection{Effectiveness of degradation indicators}

All the 106 samples were grouped by their severity level determined by the experts in the field. 
All those samples falling into the same severity group were analyzed statistically. Listed in Table 1 are mean, standard deviation, and range by severity groups for the three selected indicators. There are 15 and 11 observations falling in the severe and moderate classes, respectively. The number of observations in the slight and intact groups is higher at 22 and 58, respectively. Such an imbalanced distribution of observations with degradation intensity reflects closely the degradation reality in the study area. Namely, the majority of wetlands are healthy, and a minority of them are degraded.

\subsubsection{Moisture content}

As degradation intensity rises from intact to severe, the mean moisture content of the underlying soil decreases quickly from $54.33 \%$ to $24.37 \%$ (Table 1). Associated with this decrease is the increasingly smaller standard deviation that reaches the minimum $(7.33 \%)$ at the severe level. However, there is little difference in mean moisture content between the moderate and severe levels of degradation. This indicator seems to be incapable of revealing the precise degradation severity if it is at the moderate level and beyond. This is explained by the fact that after the surface water has been depleted to such a level, there is little change in moisture content at $10 \mathrm{~cm}$ below the surface, even though the range of moisture content is smaller at a more severe level. This limitation of moisture content in indicating wetland degradation level can be avoided by measuring it at a depth closer to the surface, such as $5 \mathrm{~cm}$. However, the closer the measurement to the surface, the more it is subject to fluctuations in climate condition. In order to generate reliable measurements, moisture has to be measured at the same spot repeatedly so as to eliminate temporal variations.

\subsubsection{Vegetative cover}

The surface of intact wetlands is well covered by vegetation at an average percentage of $78.3 \%$ (Table 1). However, such a high mean cover cannot disguise the fact that the actual cover can be as low as $10 \%$. Some types of wetlands (e.g., lacustrine and riverine) are not degraded even if their vegetative cover is $<20 \%$. Since most of the measurements were taken terrestrially, the measured vegetative cover has a smaller range of variation than the reality. Associated with this large range of vegetative cover is the largest standard deviation (25.84\%) at the intact stage, the highest among the four degradation intensities. At the slight degradation level, vegetative cover (80.9\%) is actually higher than that at the intact level. Some marshy wetlands have small pools of water distributed among them. Although not covered by vegetation, they do not manifest degradation. In general, vegetative cover is related negatively to degradation intensity beyond the slight degradation level. The worse the degradation intensity, the lower the vegetative cover. Despite this relationship, vegetative cover still has a very large range (10-99\%) at the severe level, almost the same as at the intact and slight levels. Therefore, vegetative cover is not a perfect indicator of degradation intensity if it has a very low level (e.g., within the slight degradation level).

\subsubsection{Density of pika burrows}

Wetlands unaffected by degradation are distributed with few pika burrows because the wet ground deters the invasion of pikas (Table 1). The density averages less than one burrow per $9 \mathrm{~m}^{2}$ among intact wetlands. Despite the presence of such burrows, there are no clear signs of soil erosion. Average density of pika burrows rises to around 4.4 per $9 \mathrm{~m}^{2}$ at the slight and moderate levels of degradation. The higher than expected density at the slight level of degradation is caused by one anomaly of 21 holes in one sample plot. If this anomaly is excluded, the mean density drops to 3.71 . The highest density (4.36) occurs to the moderate level of degradation, beyond which the density becomes noticeably smaller (3.0). The lower density at the severe level of degradation is explained by the abandonment of the affected sites by pikas when little original vegetation remains at this stage. The absence of suitable forage forces them to migrate elsewhere. Pika burrows will be eventually covered up by regenerated vegetation. Unlike the mean density, the range of burrow density shows little variation at all degradation levels, very similar to that of moisture content and vegetation cover. The nonlinear relationship between burrow density and degradation intensity suggests that it is not the perfect indicator of degradation intensity, either. 
Table 1 Statistical values of major degradation indicators by degradation intensity

\begin{tabular}{|l|l|l|l|l|l|l|l|l|l|l|l|}
\hline $\begin{array}{l}\text { Degradation } \\
\text { severity }\end{array}$ & \multirow{2}{*}{ No. } & \multicolumn{4}{|c|}{ Moisture content (\%) } & \multicolumn{3}{c|}{ Grass cover (\%) } & \multicolumn{3}{c|}{ Density of pika burrows } \\
\hline Intact & 58 & 54.33 & 16.85 & $32.8-100$ & 78.30 & 25.84 & $10-100$ & 0.8 & 1.49 & Range \\
\hline Slight & 22 & 36.92 & 13.59 & $18.3-66.3$ & 80.90 & 19.25 & $10-100$ & $4.5\left(3.71^{*}\right)$ & $4.35\left(2.37^{*}\right)$ & $0-21$ \\
\hline Moderate & 11 & 24.4 & 12.86 & $18.0-62.0$ & 55.45 & 18.9 & $20-85$ & 4.36 & 1.91 & $1-7$ \\
\hline Severe & 15 & 24.37 & 7.33 & $15-44.6$ & 36.53 & 23.4 & $10-88$ & 3.0 & 1.84 & $0-7$ \\
\hline
\end{tabular}

Notes: * means after exclusion of one anomaly, the same below; SD represents standard deviation; No. represents numbers of observation.

Table $2 \mathrm{t}$-test results for the mean values of indicators at neighboring degradation levels (level of significance: $\alpha=$ 0.05 , two-tail)

\begin{tabular}{|c|c|c|c|c|c|c|}
\hline \multirow{2}{*}{$\begin{array}{l}\text { Degradation } \\
\text { indicators }\end{array}$} & \multicolumn{2}{|c|}{$\begin{array}{l}\text { Intact-Slight } \\
|\mathrm{t}| \geq[\mathrm{t}, \mathrm{p}=0.975, \mathrm{df}=78]\end{array}$} & \multicolumn{2}{|c|}{$\begin{array}{l}\text { Slight-Moderate } \\
|\mathrm{t}| \geq[\mathrm{t}, \mathrm{p}=0.975, \mathrm{df}=31]\end{array}$} & \multicolumn{2}{|c|}{$\begin{array}{l}\text { Moderate-Severe } \\
|\mathrm{t}| \geq[\mathrm{t}, \mathrm{p}=0.975, \mathrm{df}=24]\end{array}$} \\
\hline & $\begin{array}{l}\text { Calculated t } \\
\text { value }\end{array}$ & $\begin{array}{l}\text { Null } \\
\text { hypothesis }\end{array}$ & Calculated t value & $\begin{array}{l}\text { Null } \\
\text { hypothesis }\end{array}$ & $\begin{array}{l}\text { Calculated } \mathrm{t} \\
\text { value }\end{array}$ & $\begin{array}{l}\text { Null } \\
\text { hypothesis }\end{array}$ \\
\hline $\begin{array}{l}\text { Moisture } \\
\text { content }\end{array}$ & $4.34>2.0$ & Rejected & $2.54>2.04$ & Rejected & $0.08<2.06$ & Accepted \\
\hline $\begin{array}{l}\text { Vegetative } \\
\text { cover }\end{array}$ & $0.43<2.0$ & Accepted & $3.60>2.04$ & Rejected & $2.20>2.06$ & Rejected \\
\hline $\begin{array}{l}\text { Density of } \\
\text { pika burrows }\end{array}$ & $\begin{array}{l}5.70>2.0 \\
\left(6.56^{*}\right)\end{array}$ & Rejected & $0.10<2.04\left(0.79^{*}\right)$ & Accepted & $1.83<2.06$ & Accepted \\
\hline
\end{tabular}

Notes: ** means are not statistically different; means results obtained after the exclusion of one anomaly.

The mean values in Table 1 were t-tested to see whether they were significantly different across adjacent intensity classes statistically. Results show that the difference in moisture content between the moderate and severe classes is not statistically significant at $\alpha=0.05$ (two-tail) (Table 2). The null hypothesis is rejected for one of the three differences between adjacent degradation classes for vegetative cover and moisture content alike. Thus, moisture content and grass cover appear to be equally effective, even though the rejection takes place at different intensity levels. For moisture content, the rejection occurs at the more severe level whereas it takes place at a lesser severity level for vegetative cover. By comparison, two out of the three differences in mean values across neighboring degradation levels are not statistically significant for pika burrow density, suggesting it is the least reliable indicator of the three. This situation remains unchanged even after the anomaly of 21 burrows in one plot was excluded from analysis. If degradation takes place beyond the slight level, there are no significant differences in burrow density between different intensity levels. For this reason this indicator is not analyzed further.

\subsection{Threshold of wetland degradation}

In order to explore the threshold of wetland degradation, soil moisture content is plotted against vegetative cover for the 106 samples, with their level of degradation intensity denoted by color (Figure 2). In general, severely degraded wetlands are clustered in the lower left corner of the diagram where both moisture content and vegetative cover are very low. However, four sites with a vegetative cover in excess of $60 \%$ are still graded severely degraded because of their low moisture content (e.g., <25\%). Such vegetation is likely regenerated toxic species not favored by livestock. Most of the moderately degraded wetlands are clustered around the middle-left position where moisture level is the lowest but vegetative cover ranges from $55 \%$ to $<80 \%$ except three that have a vegetative cover of $<40 \%$, all having a wide range of moisture content. All slight degradation sites have a vegetative cover of $>60 \%$, most of which have a moisture content above $35 \%$. However, a few have a low moisture content comparable to that of the severe and moderate classes. By comparison, most of the intact class has a vegetative cover confined to $80-100 \%$. A number of sites with a vegetative cover below 20\% are still not degraded. Such sites represent water-abundant riverine and lacustrine wetlands. This plot confirms once more that neither vegetative cover nor soil moisture content is a perfect indicator of wetland degradation severity because the same criteria are inapplicable to different types of 
wetlands that vary widely in their moisture content and vegetative cover.

A close scrutiny of Figure 2 reveals that few sites with a moisture content over 50\% are degraded. In other words, wetlands seldom face the risks of degradation over this moisture content level. Therefore, this content level is regarded as the threshold for wetland degradation to take place. The gradual depletion of water from the wetlands will not show any symptoms of degradation unless the underlying soil moisture content drops below 50\%. This concept of wetland degradation threshold was introduced by Lindig-Cisneros et al. (2003) who examined all indicators to see whether there is a critical limit above which wetland degradation occurs. In contrast to moisture content, there appears to be no vegetative cover threshold for wetland degradation to take place. For this reason, of the two indicators, vegetative cover tends to be a more reliable indicator than moisture content.

\section{Discussion}

None of the three analyzed wetland features are perfect indicators of degradation severity for various reasons, the most important being the nonlinearity of degradation itself. Namely, wetland degradation does not emerge unless water reserve in the wetland falls below a critical threshold. However, the soil moisture content measured at 10 $\mathrm{cm}$ below does not seem to be very sensitive to the level of degradation beyond the moderate level. On the other hand, vegetative cover alone is unable to capture the degradation severity precisely. The effectiveness of these indicators can be improved for the realistic and reliable assessment of wetland condition by considering the following factors: duration of degradation, nature of vegetation, and wetland type.

\subsection{Stability of degradation}

The four levels of degradation graded in this study fall into two groups in terms of their stability: permanent and transitory. The former refers to the long-term state, and includes intact and severe degradation. Encompassing slight and moderate degradation, transitory degradation is shorttermed. The transitory nature of slight and moderate degradation is attributed to its tendency of evolving to other intensities in both directions as the external conditions change. In other words, they are relatively dynamic and unstable. If the external conditions fluctuate, the degradation intensity will change to the next level. However, this is not exactly the case for severely degraded wetlands. For instance, the process of severe degradation may still persist for some types of wetland even after this stage is reached. On the other hand, there is no further differentiation between the newly degraded wetlands at this severity level and those that have been degraded at this level for some time. In other words, degradation is not linear beyond this stage. Such non-linearity explains why moisture content is not effective at differentiating moderate from severe degradation. One possible way of resolving this varying instability of wetland degradation is to make use of exotic or invasive species of grasses whose presence is also indicative of the level of degradation. A more stable state of degradation at the severe level allows more exotic species to invade and to become established, and hence a more severe level of degradation. This brings out 
the nature of vegetation cover.

\subsection{Nature of vegetative cover}

In the literature the appearance of plant communities and the emergence of specific species were reported to be indicative of wetland degradation, for instance, dominance of Kobresia tibetica in intact sites but absence at the advanced stage of degradation (Hou et al. 2009). As degradation proceeds, dominant plants of hygrophytes are gradually replaced by mesophytes and xerophytes, suggesting the evolution from marsh to xerophytic vegetation being indicative of wetland degradation. Degraded azonal $K$. schoenoides swamps on the Qinghai-Tibet Plateau are succeeded by Carex sagaensis grazing pastures (Miehe et al. 2011). An increase in the presence of exotic invasive plants is indicative of wetland degradation (Zebardast and Jafari 2011). However, the relationship may not be linear (e.g., the amount of invasive species may not change after soil moisture drops to a certain level). Analysis of ten piedmont wetlands, both intact and degraded at a wide range of severity levels, reveals that intact wetlands have a surface almost completely covered by grass (Table 3 ). The $1 \%$ surface cover is water in small pools, implying that the surface is totally saturated with moisture. By comparison, degraded sites have a vegetative cover as high as $71.8 \%$, even though some of it is regenerated grasses of unpalatable, secondary species that are not favoured by either livestock or pikas. Thus, vegetative cover alone is insufficient in depicting the degradation severity completely.

In order to capture degradation intensity more precisely, the nature of remaining vegetation must be differentiated by species in addition to coverage. The enumeration of vegetative cover of both palatable and toxic species by proportion will likely increase the effectiveness of vegetative cover in indicating the precise level of degradation intensity. Nevertheless, vegetative cover still faces ambiguity in becoming the perfect indicator even if it is further broken down into primary (e.g., original) and secondary (e.g., regenerated, mostly invasive and toxic) if different types of wetlands are treated indiscriminately. One possible way of remedying this imprecision is to take one more variable of surface water area into simultaneous consideration with vegetative cover. Surface water area can be quantified with the assistance of vertical aerial photographs or satellite images (for broad area only).

Table 3 Comparison of characteristics of intact and degraded piedmont wetlands.

\begin{tabular}{|l|l|l|l|l|} 
Feature & $\begin{array}{l}\text { MGC } \\
(\%)\end{array}$ & $\begin{array}{l}\text { ARH } \\
\left(9 \mathrm{~m}^{2}\right)\end{array}$ & $\begin{array}{l}\text { MC } \\
(\%)\end{array}$ & $\begin{array}{l}\text { Degradation } \\
\text { intensity }\end{array}$ \\
\hline Intact (10) & 99.0 & 1.3 & 61.4 & Intact \\
\hline Degraded (10) & $71.8^{*}$ & 4 & 23.8 & 2 Slight \\
\hline
\end{tabular}

Notes: MGC $=$ Mean Grass Cover; ARH = Ave. numbers of Rodent Holes; MC = Moisture Content; * means including regenerated secondary species not useful for grazing.

\subsection{Influence of wetland type}

The exact relationship between a wetland degradation indicator and degradation severity as reported above is obscured by wetland type. Wetlands in the study area exhibit a huge diversity in their form, vegetative cover, and surface water area (Gao 2011). The wide variations in surface water area and vegetative cover among different types of wetlands can be avoided by partitioning the 106 samples by wetland types. However, this is impractical given the small number of samples collected. More importantly, not all wetlands have been degraded to the same degree (e.g., lacustrine wetlands are not easily degradable). Analysis of sub-samples for some types of wetland is unlikely to yield a holistic picture about the effectiveness of the three indicators. This issue could be avoided by modifying the criteria of degradation severity for different types of wetland. One possible method of taking surface water into consideration is to analyze wetland degradation by wetland type. For instance, water-abundant wetlands with lots of surface water and hence a lower vegetative cover is incomparable to alpine wetlands of a low water reserve but a high vegetative cover. A vegetation cover of $40 \%$ is the minimum for healthy wetland, below which it has been degraded while the threshold can be as low as $5 \%$ for lacustrine and riverine wetlands. In this way the same degradation criteria of a given indicator are not applied to all kinds of wetlands indiscriminately. More research is needed to come up with specific modification of the degradation criteria for 
different wetland types.

\section{Conclusions}

Data on wetland health were collected from wetlands that have been degraded to various levels in Maduo County on the Qinghai-Tibet Plateau. Analysis of these field data reveals that pika burrows have a density ranging from 0 to 21 per 9 $\mathrm{m}^{2}$. Grass cover has a range of $0-100 \%$ while soil moisture measured at $10 \mathrm{~cm}$ below the surface varies from o to $100 \%$. After wetland degradation at the 106 sites were enumerated at four intensity levels from intact to severe, it is found that one of the three differences in mean vegetative cover between neighbouring classes of intensity level (intact and slight degradation) was insignificantly different statistically. In contrast, the mean value of soil moisture bears a statistically significant difference from that of the adjacent grade except that between moderate and severe. These two indicators complement each other in that one is insensitive to low levels of degradation while another is insensitive to a higher degree of degradation. Density of pika burrows is not a reliable indicator as two of the three differences between adjacent severity classes in mean density of pika burrows are not significantly different statistically. This situation remains unchanged even after one anomaly is excluded from analysis. Thus, the effectiveness of the three indicators in indicating degradation severity of plateau wetlands

\section{References}

Arthur AD, Pech RP, Bu J, et al. (2007) Grassland degradation on the Tibetan Plateau: the role of small mammals and methods of control. Canberra: Australian Centre for International Agricultural Research Technical Reports No. 67, p 35 .

Avis CA, Weaver AJ, Meissner KJ (2011) Reduction in areal extent of high-latitude wetlands in response to permafrost thaw. Nature Geoscience 4(7): 444-448. DOI: 10.1038/ ngeo1160.

Cvetkovic M, Chow-Fraser P (2011) Use of ecological indicators to assess the quality of Great Lakes coastal wetlands. Ecological Indicators 11(6): 1609-1622, DOI: 10.1016/ j.ecolind.2011.04.005.

Fan NC, Zhou WY, Wei WH, et al. (1999) Rodent pest management in Qinghai-Tibet alpine meadow ecosystem. In: Singleton GR, Hinds LA, Leirs H, Zhang $Z$ (eds.), Ecologically-based Management of Rodent Pests. Australian Centre for International Agricultural Research: Canberra, pp is vegetative cover, soil moisture content, and pika burrow density in the descending order. Their ineffectiveness is attributed to the non-linearity of wetland degradation. It does not occur when the moisture content threshold is around 50\%. No such a threshold is found for vegetative cover. In order for these indicators to be more effective, it is recommended that soil moisture be measured at a depth much closer to the surface, and vegetative cover be further differentiated to include the proportion of exotic species, and different criteria of degradation severity be applied to different types of wetland.

\section{Acknowledgements}

This research was supported by the International Science \& Technology Cooperation Program of China (Grant No. 2011DFG93160, 2011DFA20820), the National Natural Sciences Foundation of China (Grant No. 41161084), Special Fund for Agroscientific Research in the Public Interest (Grant No. 201203041) and the Scientific Research Collaboration and Training of Top Scientists project (Document No. 2010-1595), Department of International Exchange \& Cooperation of the Chinese Ministry of Education. We thank Professor CHEN Gang, Mr CHEN Qingyu and Mr SONG Yu-lin from Qinghai University for their support during the field trips of this study. Three anonymous reviewers provided notable amendment suggestions on this manuscript.

285-304.

Fennessy MS, Jacobs AD, Kentula ME (2007) An evaluation of rapid methods for assessing the ecological condition of wetlands. Wetlands 27(3): 543-56o.

Gao J (2011) Sanjiangyuan wetlands: Introduction and overview. In: Chen G, Li XL, Gao J, Brierley G (eds.) Wetland Types, Evolution and Their Rehabilitation in the Sanjiangyuan Region, Qinghai People's Press, pp 1-8.

Gao YH, Schumann M, Zeng XY, et al. (2011) Changes of plant communities and soil properties due to degradation of alpine wetlands on the Qinghai-Tibetan plateau. Journal of Environmental Protection and Ecology 12(2): 788-798.

Hou Y, Guo ZG, Lon RJ (2009) Changes of plant community structure and species diversity in degradation process of Shouqu wetland of Yellow River. Chinese Journal of Applied Ecology 2O(1): 27-32. (In Chinese)

Li GQ, Kan AK, Wang XB, et al. (2010) Distribution of degraded wetlands and their influence factors in Qomolangma National 
Nature Reserve. Wetland Science 8(2): 110-114. (In Chinese)

Li M, Xu R, Huang W, et al. (2011) A study on the effects of the surrounding faults on water loss in the Zoige Wetland, China. Journal of Mountain Science 8(4): 518-524. DOI: 10.1007/ s11629-011-2060-4.

Li XL, Perry GLW, Brierley G, et al. (2012) Quantitative assessment of degradation classifications for degraded alpine meadows (heitutan), Sanjiangyuan, western China. Land Degradation \& Development, DOI: 10.1002/ldr.2154.

Lindig-Cisneros R, Desmond J, Boyer KE, et al. (2003) Wetland restoration thresholds: Can a degradation transition be reversed with increased effort? Ecological Applications 13(1): 193-205. DOI: 10.1890/1051-0761(2003)013[0193:wrtcad] 2.0.co;2.

Liu C, Xie G, Huang H (2006) Shrinking and drying up of Baiyangdian Lake wetland: A natural or human cause? Chinese Geographical Science 16(4): 314-319. (In Chinese)

Ma K-M, Guo L, Zhang Y (2009) Landscape assessment on wetland degradation during thirty years in Jiansanjiang region of Sanjiang plain, Northeast China. Acta Ecologica Sinica 29(6): 3126-3135. (In Chinese)

Miehe G, Miehe S, Bach K, et al. (2011) Plant communities of central Tibetan pastures in the Alpine Steppe/Kobresia pygmaea ecotone. Journal of Arid Environments 75(8): 711723. DOI: 10.1016/j.aridenv.2011.03.001.

Qi DC, Li GY (2007) Status, causes and protection countermeasures of wetland degradation in Maqu county in the Upper Yellow River. Wetland Science 5(4): 341-347. (In Chinese)

Teferi E, Uhlenbrook S, Bewket W, et al. (2010) The use of remote sensing to quantify wetland loss in the Choke
Mountain range, Upper Blue Nile basin, Ethiopia. Hydrology and Earth System Sciences 14(12): 2415-2428. DOI: 10.5194/ hessd-7-6243-2010.

Van Dam RA, Camilleri C, Finlayson CM (1998) The potential of rapid assessment techniques as early warning indicators of wetland degradation: A review. Environmental Toxicology and Water Quality 13(4): 297-312. DOI: 10.1002/(SICI)10982256(1998)13:4<297::AIDTOX3>3.0.C O;2-2.

Wang G, Li Y, Wang Y, et al. (2007) Typical alpine wetland system changes on the Qinghai-Tibet Plateau in recent 40 years. Acta Geographica Sinica 62(5): 481-491. (in Chinese)

Wang Y, Zhou D, Sun Y (2011). Assessment of the ecological health of wetlands in Honghe supported by RS and GIS techniques. Acta Ecologica Sinica 31(13): 3590-3602. (In Chinese)

Wu SS, Zhang ZL, Chen M, et al. (2009) Change of coastal wetlands and analysis of its driving reasons along south coast of the Laizhou Bay. Wetland Science 7(4): 373-378. (In Chinese)

Zebardast L, Jafari HR (2011) Use of remote sensing in monitoring the trend of changes in Anzali wetland in Iran and proposing environmental management solution. Journal of Environmental Studies 37(57): 57-64.

Zhang Y, Wang G, Wang Y (2011) Changes in alpine wetland ecosystems of the Qinghai-Tibetan plateau from 1967 to 2004. Environmental Monitoring and Assessment 180(1-4): 189-199, DOI: $10.1007 /$ s10661-010-1781-0.

Zhang ZQ, Zhou DM, Luan ZQ, et al. (2010) A study on quantification and spatial-temporal patterns of wetlands soil moisture. European Space Agency (Special Publication) ESA SP, Volume 684 SP, p 8. 